\title{
Diagnostic Outcome of Bone Marrow Aspiration in a Tertiary Hospital in Ondo State, Nigeria
}

\section{Patrick Olanrewaju Osho", ", Maltida Adesuwa Ojo ${ }^{1}$, Victor Koledoye ${ }^{3}$, Aisha Ndidi Okunnuga ${ }^{2}$, Oluwatosin Idowu Oni ${ }^{3}$}

${ }^{1}$ Department of Hematology and Immunology, University of Medical Sciences, Ondo City, Nigeria

${ }^{2}$ Department of Radiation and Clinical Oncology, University of Medical Sciences, Ondo City, Nigeria

${ }^{3}$ Department of Haematology, University of Medical Sciences Teaching Hospital, Akure, Nigeria

Email address:

droshopo@unimed.edu.ng (P. O. Osho), matildaojo4@gmail.com (M. A. Ojo), vkoledoye@yahoo.com (V. Koledoye), aishaokunnu@gmail.com (A. N. Okunnuga),godsprince805@gmail.com (O. I. Oni)

${ }^{*}$ Corresponding author

\section{To cite this article:}

Patrick Olanrewaju Osho, Maltida Adesuwa Ojo, Victor Koledoye, Aisha Ndidi Okunnuga, Oluwatosin Idowu Oni. Diagnostic Outcome of Bone Marrow Aspiration in a Tertiary Hospital in Ondo State, Nigeria. American Journal of Laboratory Medicine.

Vol. 6, No. 2, 2021, pp. 17-21. doi: 10.11648/j.ajlm.20210602.11

Received: March 3, 2021; Accepted: March 15, 2021; Published: April 12, 2021

\begin{abstract}
Bone marrow examination is a vital study carried out to attain a positive diagnosis of hematological disorders in a resource low income country like Nigeria specifically in Ondo state. Bone marrow is a main spot of hematopoiesis. It is also a major tool used in diagnosis of non-hematological disorders. The main aim of this study is to examine the outcome of bone marrow aspiration in Ondo state. A retrospective 8 years study was carried out between 2012 till 2020 at the University of medical sciences (former Kidney care center, Trauma center and State specialist hospital, Akure) Ondo state. Age, sex, location of patients, bleeding disorders, various indications and diagnosis were analysed using SPSS version 23. A total of 115 bone marrow aspirations were done at University of medical sciences, Ondo. Majority of the patients were male $(58.3 \%)$ while $41.7 \%$ were females. Most are aged above 45 (46.1\%). The most common indication was Anaemia specifically the moderate anaemia (52.2\%). Commonest diagnostic findings in our study was Leukemia (42\%) followed by Megaloblastic anaemia and Multiple myeloma (12.1\%). Given the increase in the prevalence of Megaloblastic anaemia and Iron deficiency anemia globally, our study showed high prevalence rate of leukemia specifically chronic myeloid leukemia. The predominance of leukemia among diagnostic findings in our study has been related to the proximity to tertiary health facility. Low number of cases of other diagnostic findings can be due to lack of accessibility to an improved health center especially those in the rural areas and low population of people in the state. Early diagnosis should be done for effective management of these hematological disorders. Good family support and improved health care system with well trained personnel will help in management of the disease.
\end{abstract}

Keywords: Hematological Disorders, Hematopoiesis, Bone Marrow Examination, Megaloblastic Anaemia, Multiple Myeloma

\section{Introduction}

Bone marrow, one of the body's largest organs, is the main spot of hematopoiesis. The main purpose of bone marrow is to supply developed hematopoietic cells which helps in blood circulation in a stable form as well as their response to high pathological demands. It is used for analysis, approval and/or stage hematological malignances. It helps to assess cytopenias, thrombocytosis, leukocytosis, anemias, and iron status. It is also an important tool in diagnosis of nonhematological disorders such as storage disorders [1].

Bone marrow aspiration (BMA) is an invasive procedure that involves the collection of bone marrow sample via the use of bone marrow needle aspiration and aspirate is obtained, smeared and stained with Rowmanosky stains and cytological details of the marrow elements are examined 
under light microscope $[2,3]$. This procedure is an easy and relatively safe process done in hospitals for the diagnosis and management of hematological and non-heamatological disorders [4]. In vivo bone marrow aspiration had been carried out as early as 1876 on a patient with leukaemia which involve the use of a regular wood drill by Mosler to draw bone marrow particles [5]. Clinical importance of BMA as at today goes beyond cytologic assessment of haematopoietic and non-haematopoietic marrow cells alone. Additional diagnostic assays done on BMA specimens include cytochemical/ special stainings, immunophenotyping, microbiologic tests, cytogenetic analysis and molecular studies [6].

Bone marrow aspiration (BMA) provides marrow cellularity, its structure and stage of development of different blood cells [7]. It also helps in diagnosis and staging of hematological disorders especially leukemias. Informations regarding the presence of hemoparasites within the bone marrow, presence of infiltrates and storage diseases are also provided using bone marrow aspiration. Clinical conditions that involves the process of bone marrow aspiration includes unexplained cytopenia (anaemia, leucopenia, thrombocytopenia), unexplained splenomegaly and lymphadenopathy, diagnosis of acute leukaemia, megaloblastic anaemia, plasma cell myeloma, myelophthisic anaemia, monitoring of cancer chemotherapy and other chromosomal studies and molecular genetic analysis $[8,9]$. It is also required for patients with suspected marrow diseases with inconclusive diagnosis after several tests such as the peripheral blood film (PBF), full blood count (FBC) and ancillary tests is carried out. Study by Bashawri recognized pancytopenia, leukemia, staging of lymphoma among others as the major indications for BMA [10]. a study done in Nigeria showed anemia as major indication for BMA [11].

A study done in America stated the relevance of bone marrow aspiration in determination of the causes of peripheral macrocytosis and megaloblastic anaemia was identified due to lack of vitamin B12 and or folate and deviation in metabolism among other causes of macrocytosis such as alcohol ingestion, hypothyroidism, myelodysplastic syndrome (MDS) haemolysis and myeloproliferative diseases [12].

Despite being a strong diagnostic tool, BMA is associated with some risks or complications which includes hemorrhage, pain, infections and on rare occasions arterovenous fistulae [13]. Pain is associated with BMA because the technique is done invasively. In addition to anesthetics, hypnosis and cognitive behavioral therapies are used to relieve the pain in children during the procedure. However, local anesthetics are used for adults to ease the pain [14].

Laboratory tests such as FBC and PBF as well as clinical details of the patients are obtained before performing BMA. Patient are adequately counselled and informed consent are required before Bone marrow aspiration is done. After the collection of bone marrow via aseptic condition using a BMA needle, smear is made and the left over specimen is kept in EDTA anticoagulant bottle and extra processing is done in the hematology laboratory [7].

Due to less information on the outcome of bone marrow aspiration done in Ondo state, this study aims to examine the outcome of bone marrow aspiration in Ondo state.

\section{Materials and Methods}

This is a retrospective study of all cases of hematological conditions diagnosed and managed between 2012-2020 at University of medical sciences teaching hospital (former Kidney care center, Trauma center and State specialist hospital, Akure), Ondo state. Patient's case notes, bone marrow aspiration results and histopathology results were materials used for this study. The patients were grouped according to age, sex, location, type of sedative used, aspiration sites, number of aspirations done, trephine biopsy and hemostasis profile. Clinical details of the patients, intra procedure details were recorded.

All data were recorded and analysed using SPSS version 23. This was done to show the prevalence of the indications and diagnosis among patients with these hematological malignancies.

\section{Results}

One hundred and fifteen (115) bone marrow aspirations were done at University of Medical sciences teaching hospital, Ondo state. Majority of the patients were aged above 45 years $(46.1 \%) .67(58.3 \%)$ were males while 48 $(41.7 \%)$ were females. Most BMA procedures $(79.1 \%)$ were done on patients during admission while $20.9 \%$ were outpatients. $33 \%$ of the patients had thrombocytopenia while $2.6 \%$ of the patients had coagulopathy, majority of the patients $(64.4 \%)$ had no bleeding disorder. Most of the patients for BMA were given lidocaine $(88.7 \%)$, some were on pentazocine $(8.7 \%)$, while few were on diazepam $(2.6 \%)$. Most of the aspirates $(86.1 \%)$ were taken from the posterior iliac crest while $11.3 \%$ of the aspirates were taken from the anterior iliac crest, although fewer number of aspirates $(2.6 \%)$ were taken from the sternum especially in obese patients. Single aspirations were done in most of the patients $(91.3 \%)$ while multiple aspirations were done in $8.7 \%$ of the patients. The most common indications for BMA cytology was anaemia which was seen in $92.2 \%$ of the patients, although most of the patients $(52.2 \%)$ had moderate anaemia, followed by severe anaemia $(32.2 \%)$ with a few number of patients $(7.8 \%)$ experiencing mild anaemia. $32.1 \%$ of the patients had fever with larger percentage seen among males. $13.9 \%$ of male patients and $7.8 \%$ of the female patients had splenomegaly while pancytopaenia and lymphadenopathy was found in $18.3 \%$ of the patients. $13 \%$ of the patients had chronic back pain while testicular swelling was seen in only $0.9 \%$ of the patients. Most of the patients (41.7\%) had suspected leukemia and $8.7 \%$ of the patients had pathologic fracture. $33.1 \%$ of the patients had leukocytosis, while $29.6 \%$ had abdominal pain. Erythromelagia was seen in $0.9 \%$ of the patients same as Gum bleeding. Mucosal bleeds was seen in 
$1.7 \%$ of the patients, bilateral parestersia was seen in $2.6 \%$ of the patients. None of the patients had Jaw mass. The overall commonest diagnosis by BMA was leukemia with chronic myeloid leukemia seen in most of the patients $(15.6 \%)$, followed by CLL (14.8\%), 6.9\% of the patients had ALL, few number of the patients $(1.7 \%)$ had AML. MA and MM followed leukemia as both second most common diagnostic findings of BMA with cases seen in $12.1 \%$ of the patients. $5.2 \%$ had IDA, $0.9 \%$ had MDS. BMI of blood cancer, ET, HL, PLL were seen in $1.7 \%$ of the patients. AA, NHL, NA was seen in $6.1 \%$ of the patients. ITP, hypersplenism were seen in $2.6 \%$ of the patients. Myelofibrosis and eosinophila secondary to parasitic infection were seen in $0.9 \%$ of the patients. $4.3 \%$ had PRV

\section{Discussion}

This study showed the various indications and diagnostic outcome of bone marrow aspiration performed in a tertiary hospital in Ondo state. The age range of the patients was within 2 years- 85 years. This is in accordance with the study carried out in Jos by Egesie et al. [11],. Damulak et al [15]. A larger number of our patients were male with a male-female ratio of 1:0.7. This is similar to study done by Dachi et al, with a larger percentage of patients known to be male [16], reports in India by Khan et al, also shows dominance of male which is in correlation with our study [17]. Majority of the BMA were done on in-patient basis which is similar to study done by Adewoyin et al. in Benin City showing that most of the patient's symptoms and management required hospitalization [18]. $33 \%$ of the patients in our study had thrombocytopenia while $2.6 \%$ of the patients had coagulopathy. Majority of the thrombocytopenic patients in our study had leukemia which shows that low platelet count can be caused by leukaemia. This was supported by Mehmet Ali et al in his study that shows leukemia represented the most of the cases with thrombocytopenia [19]. It was also similar to the study by Mahabir et al. [20] which shows the effect of BMA in thrombocytopenic patients majorly to exclude other hematological malignancies like leukemia in children and myelodysplastic syndrome in adults.

The most common indications for BMA cytology in our study is Anaemia with majority of the patients with Moderate anaemia. This is similar to the studies done by Damulak et al [15] in Jos, Awwalu et al, in Zaria [21] and also Dachi et al, in Bauchi [16]. Large percentage of anaemia seen in our patients may be due to late presentation at the hospital caused by lack of funds, ignorance and patients patronizing private hospitals where further investigations are not done to find out the cause of anemia. Also, suspected leukemia had been known to be the second common indication for BMA according to our study which is in agreement with study done in Saudi by Bashawri with diagnosis and management of leukemia identified as the most common indication for bone marrow examination [10]. However, other studies identified pancytopenia as the most common indication for BMA cytology examination [22].
Major site of BMA aspiration was at the posterior ilium with few done at the anterior ilium, this is due to the fact that higher yield is gotten from the posterior ilium than the anterior ilium. This was supported in a study by Pierini et al, which a higher concentration and yield of colony-founding connective-tissue progenitors were greater when aspirate was obtained from the posterior compared with the anterior iliac crest [23] Lesser number of aspirates were taken from the sternum mostly in the obese patients by well-trained expertise due to the deadly risk of damage to the underlying structures such as heart and major vessels [24]. However, our study is in contrast with that done in Bauchi that reported right anterior iliac spine as the major site of bone marrow aspiration (45.6\%) [16].

Leukemia was the most common diagnostic findings in our study $(42 \%)$ of which CML had the highest frequency (15.6\%), followed by CLL (14.8\%), ALL (6.9\%) was more common than AML (1.7\%) in our study. this was in agreement with study done by Gohil et al with higher prevalence of ALL seen in his study [1]. However study by Egesie et al, was in contradiction showing higher prevalence seen in AML patients [11]. Also studies done by Fatima et al, Adewoyin et al, shows leukemia being the most common diagnostic findings among patients undergoing BMA $[18,25]$ Other similar studies shows a frequency range of leukemia from low as $24 \%$ to high as $68 \%[26,27]$. The prevalence of leukemia in our study is based on the closeness of the patients to tertiary health centre, although some of the patients yet to be diagnosed live in rural areas with less accessibility to well-equipped tertiary hospitals needed to carry out diagnostic findings thereby causing late diagnosis of such patients. This was in correlation with study done by Akaba et al, which shows the prevalence of CLL associated with proximity of the patients to tertiary hospital [28]. However, some of these patients leaving in urban city travel down to their respective homes for family support due to lack of funds for management of these hematological malignances.

Megaloblastic anemia and Multiple myeloma were the second most common diagnostic findings seen in our study. This is in conflict with study by Dachi et al which shows MA was the most common diagnostic findings in BMA [16]. The high predominance of MA could be traced to the standard of living of the patients with most of them having to overcook their food most especially vegetables containing folates. This is in agreement done in India by Khan et al [17]. Iron deficiency anemia accounts for $5.2 \%$ in our study. This is in agreement with study done by Damulak et al in Jos with a prevalence rate of IDA accounted for $4.8 \%$ of the cases [15]. The low case of Iron deficiency anemia in our study may be due to poverty with majority being low income earners, adverse economic effects of expanded religion, weather conditions and ethnic crisis

Aplastic anaemia was seen in 7 cases (6.1\%). This was also in correlation with a study by Gohil et al with $6.19 \%$ prevalence of AA studied [1]. 


\section{Conclusion}

Bone marrow aspiration is a suitable procedure in diagnosis and management of a wide range of hematological and some non-hematological diseases particularly in a low resource area like Ondo state. Leukemia is the most common diagnostic findings among patients undergoing BMA in our study followed by Megaloblastic anaemia and Multiple myeloma. More cases of hematological malignancies could not be accounted for due to lack of accessibility to a good health care facility at low cost in some rural areas in the state and inability of private practitioners to ensure adequate investigation of the cases and early referral of patients. Also inadequate well skilled personnel in both at peripheral and tertiary hospitals in a developing country can contribute to poor diagnosis and management of the hematological malignancies. Lastly, low population in the state can lead to less prevalence of cases of hematological malignancies.

\section{Recommendation}

Early diagnosis should be carried out on patients with hematological malignancies to aid in effective treatment and management of the patients.

Improved health care system should be provided by the government in developing areas such as rural areas in order to help easy access to health facilities which aids in early diagnosis and management if patients with hematological malignancies. Well trained expertise should also be made available in the health Centres to help carry out procedures required for BMA. Good family support should also be provided for patients with these hematological malignancies to ease the challenges faced during management of these diseases

Fears and anxiety among patients can be alleviated by educating the patients about the method, indication and possible risks associated with it. Local anesthesia should be allowed before the procedure to ease the pain related to the procedure.

\section{Acknowledgements}

The Authors acknowledge the assistance of all the Staff at the Haematology/Virology Laboratory, University of Medical Sciences Teaching Hospital, Akure.

\section{Conflict of Interest}

The Authors declare no conflict of interest

\section{References}

[1] Gohil M, Rathod K. Bone Marrow Aspiration Cytology Study in a Tertiary Care Center, Gujarat, India. Int J Sci Stud 2018; 5 (10): 11-14

[2] Gluckman E. Choice of the donor according to HLA typing and stem cell source. In: Apperley J, Carreras E, Gluckman E, Masszi T, editors. EBMT Handbook Haemotopoietic Stem cell
Transplantation. 6th ed., Vol. 6. Nigeria: EBMT Handbook; 2012. p. 90-107.

[3] Catovsky D, Tuddenham E, editors. Postgraduate Haematology. 6th ed. Massachusetts USA: Blackwell Publishers Ltd; 2011. pp 1-11.

[4] Rock WA Jr., Stass SA, editors. Handbook of Hematologic Pathology. New York, NY: Marcel Dekker, Inc.; 2000. p. 126.

[5] Ryan DH, Felgar RE. Examination of the marrow. In: Lichtman MA, Kipps TJ, et al (eds). William's haematology 7ed. New York, McGraw Hill 2006; 3: 21-31.

[6] Lee SH, Erber WN, Porwit A, et al: ICSH guidelines for the standardization of bone marrow specimens and reports. Int $\mathrm{J}$ Lab Hematol 2008; 30: 349 - 364.

[7] Bain BJ. Bone marrow biopsy morbidity: Review of 2003. J Clin Pathol 2005; 58: 406-8.

[8] Abla O, Friedman J, Doyle J. Performing bone marrow aspiration and biopsy in children: Recommended guidelines. Paediatr Child Health 2008; 13 (6): 499 - 501.

[9] Halim NKD, Famodu AA, Wemanbu SNC. Textbook of Clinical Haematology and Immunology. Indications for bone marrow aspiration. 2nd Edition, Ambik Press; 2001: 10.

[10] Bashawri LA. Bone marrow examination. Indications and diagnostic value. Saudi Med J 2002; 23: 191-6.

[11] Egesie OJ, Joseph DE, Egesie UG, Ewuga JO. Epidemiology of anaemia necessityating bone marrow aspiration cytology in Jos. Niger Med J 2009; 50: 61-3.

[12] Kaferle J, Strzoda C (2009). Evaluation of macrocytosis. Am. Fam. Physician. Pp. 203-208.

[13] Berber I, Erkurt MA, Kuku I, et al. An unexpected complication of Bone Marrow Aspiration and Trephine Biopsy: Arteriovenous Fistula. Med Princ Pract 2014; 223: 280-383.

[14] Vanhelleputte P, Nijs K, Delforge M, Evers G, Vanderschueren S. Pain during bone marrow aspiration: prevalence and prevention. J Pain Symptom Manage 2003; 26 (3): 860-6.

[15] Damulak OD, Damen JG. Diagnostic outcome of Bone marrow aspiration in a new centre in Nigeria. Glob Adv Res J Med Med Sci 2012; 1: 166-71.

[16] Dachi AF, Mustapha FG, Yuguda S, Kagu MB, Gwaram AA and Bwala P. Bone marrow aspiration cytology in Abubakar.

[17] Khan SP, Sajjad G, Shareefa A, et al. Bone marrow aspiration in haematological disorders: study at a tertiary care centre. Int J Res Med Sci 2018; 6: 2363.

[18] Adewoyin AS, Ezire ES, Adeyemi O, et al. Bone marrow aspiration cytology studies in a Tertiary Hospital Nigeria: A series of 88 cases. Ann Pathol Lab Med 2015; 2: 107-14.

[19] Erkurt MA, Kaya E, Berber I, Koroglu M and Kuku I. Thrombocytopenia in Adults. J Hematol, 2012; 1 (2-3); 44-53.

[20] Mahabir KV, Ross C, Popovis S, Sur ML et al. A blinded study of bone marrow examinations in patients with primary immune thrombocytopenia. Eur J Hematol. 2012. Available from https://doi.org/10.1111/ejh.12041 
[21] Awwalu S, Haasan A, Dogara LG, Musa AU, Waziri AD, Babadoko AA. Bone marrow aspiration in Zaria: A Three-year retrospective review. Bo Med J 2016; 13 (1): 50-55.

[22] Pudasaini S, Prasad KB, Rauniyar SK, Shrestha R, Gautaam $\mathrm{K}$, Pathak R, et al. Interpretation of bone marrow aspiration in haematological disorders. J Pathol Nepal 2012; 2: 309-12.

[23] Pierini M, Di Bella C, Dozza B, Frisoni T, Martella E, Belloti C, Remondini D, Lucarelli E, Giannini S, Donati D. The posterior iliac crest outperforms the anterior iliac crest when obtaining mesenchymal stem cells from the bone marrow. J Bone Joint Surg Am. 2013 Jun 19; 95 (12): 1101-7.

[24] Thieml H, Diem H, Haferlach T (eds). Procedures, Assays and Normal values. In: Color Atlas of hematology. Practical microscopic and clinical diagnosis. Thieme Stuttgart New York. 2ed, 2002; 2: 9-28.
[25] Fatima A and Ahmed IM. Diagnostic Outcome of Bone Marrow Aspiration in a Paediatric Centre in Hyderabad, India. 2018. JMSCR Vol 06 Issue 02 Page 1029-1037.

[26] Mussarat N, Raziq F. The incidence of underlying pathology in pan cytopenia. An experience of 89 cases. J Postgrad Med Inst 2004; 18: 76-9.

[27] Ng SC, Kuperan P, Chan KS, Bosco J, Chan GL. Megaloblastic anaemia - A review from University Hospital, Kuala Lumpur. Ann Acad Med Singapore 1988; 17: 261-6.

[28] Akaba K, Enang O, Igwilo H, Eduve V, Akaba E, Cletus O, Oshatuyi O. Demographic pattern of chronic lymphocytic leukemia in a tertiary hospital in Calabar, South-South Nigeria. Ann Afr Med 2020; 19: 203-6. 